\title{
Empathy Levels Correlate with Practical Examination Scores in Doctor of Physical Therapy Students
}

\author{
Scott Richardson \\ Franklin Pierce University, richardsons@franklinpierce.edu \\ Danika Aten \\ Franklin Pierce University, Atend18@live.franklinpierce.edu \\ Garrett Bennett \\ Franklin Pierce University, Bennettg18@live.franklinpierce.edu \\ Matthew Koster \\ Franklin Pierce University, Kosterm18@live.franklinpierce.edu \\ Hannah Svilar \\ Franklin Pierce University, svilarh18@live.franklinpierce.edu
}

Follow this and additional works at: https://nsuworks.nova.edu/ijahsp

Part of the Physical Therapy Commons

\section{Recommended Citation}

Richardson S, Aten D, Bennett G, Koster M, Svilar H. Empathy Levels Correlate with Practical Examination Scores in Doctor of Physical Therapy Students. The Internet Journal of Allied Health Sciences and Practice. 2021 Jan 01;19(2), Article 13.

This Manuscript is brought to you for free and open access by the College of Health Care Sciences at NSUWorks. It has been accepted for inclusion in Internet Journal of Allied Health Sciences and Practice by an authorized editor of NSUWorks. For more information, please contact nsuworks@nova.edu. 


\title{
Empathy Levels Correlate with Practical Examination Scores in Doctor of Physical Therapy Students
}

\begin{abstract}
Purpose: The purpose of this study was to examine if empathy levels correlate with practical examination scores in DPT students. It was hypothesized that students with higher empathy levels would receive better scores on practical examinations. Methods: Participants were a convenience sample of 49 first and second year DPT students from Franklin Pierce University in Goodyear, AZ. After obtaining informed consent, participants completed the Interpersonal Reactivity Index (IRI) to assess personal empathy. These scores were compared with participants' practical examination scores using a Spearman Rho statistical test with data analysis completed using SPSS software. Results: 49 participants ( 26 females, 23 males) with mean practical examination score $(92.5 \% \pm 0.02)$ and mean empathy score $(72.80 \pm 18.66)$. Spearman Rho correlation $\left(r_{s}=0.864, p<0.000\right)$. Conclusions: A significant positive correlation between empathy and practical examination scores in physical therapy students was found. Educators can use these findings to provide resources to students to assist with practical examination performance.
\end{abstract}

\section{Author Bio(s)}

Scott Richardson, PT, PhD, is an Assistant Professor in the Doctor of Physical Therapy program at Franklin Pierce University located in Goodyear Arizona. He has received the Advanced Competency in Home Health Care from the American Physical Therapy Association.

Danika Aten, Garrett Bennett, Matthew Koster, and Hannah Svilar are all graduate students in the Doctor of Physical Therapy program at Franklin Pierce University located in Goodyear Arizona. 


\title{
TIJAHSP
}

\section{The Internet Journal of Allied Health Sciences and Practice \\ Dedicated to allied health professional practice and education}

Vol. 19 No. 2 ISSN 1540-580X

\section{Empathy Levels Correlate with Practical Examination Scores in Doctor of Physical Therapy Students}

\author{
Scot Richardson \\ Danika Aten \\ Garrett Bennett \\ Matthew Koster \\ Hannah Svilar \\ Franklin Pierce University \\ United States
}

\begin{abstract}
Purpose: The purpose of this study was to examine if empathy levels correlate with practical examination scores in DPT students. It was hypothesized that students with higher empathy levels would receive better scores on practical examinations. Methods: Participants were a convenience sample of 49 first and second year DPT students from Franklin Pierce University in Goodyear, AZ. After obtaining informed consent, participants completed the Interpersonal Reactivity Index (IRI) to assess personal empathy. These scores were compared with participants' practical examination scores using a Spearman Rho statistical test with data analysis completed using SPSS software. Results: 49 participants ( 26 females, 23 males) with mean practical examination score $(92.5 \% \pm 0.02)$ and mean empathy score $(72.80 \pm 18.66)$. Spearman Rho correlation $\left(r_{s}=0.864, p<0.000\right)$. Conclusions: A significant positive correlation between empathy and practical examination scores in physical therapy students was found. Educators can use these findings to provide resources to students to assist with practical examination performance.
\end{abstract}

Keywords: practical examination, empathy, physical therapy, admissions 


\section{INTRODUCTION}

Meaningful clinical interactions between a physical therapist and a patient are vital to efficacious practice. Central to every patientclient relationship is empathy ${ }^{1}$ Empathy is a complex concept that involves various moral, cognitive, emotional, and behavioral elements. ${ }^{2}$ It includes the ability to understand the patient's situation including their perspective and feelings, communicate that understanding back to the patient for accuracy, and act on that understanding in a helpful and therapeutic way..$^{3-4}$ Empathy helps to build a trusting relationship between therapist and patient by encouraging a safe environment with open communication, allowing a thorough examination and overall, successful treatment. Empathy levels were compared among university students, with health students exhibiting significantly higher empathy levels than non-health students..$^{5-6}$ In a study comparing empathy levels among physical therapy students at two different institutions, empathy levels were found to vary. ${ }^{7}$ Research examining empathy in medical and nursing students found empathy to be positively correlated with more accurate diagnoses and improved treatment adherence from patients. ${ }^{4,8}$

Can empathy be taught or improved? Davis states that empathy is unteachable; that instead, "promoting attitudes and behaviors such as self-awareness, nonjudgmental positive regard for others, good listening skills, and self-confidence are suggested as important in the development of clinicians who will demonstrate an empathic willingness." 9 Studies have shown that empathy improves with training in nursing and medical students.4,10-12 There is also research examining empathy levels in DPT students. Mueller et al found improved empathy levels in DPT students after completion of an online intervention. ${ }^{13}$ Another study found that service-learning, a form of experiential education that combines student learning with meeting real community needs, and the resulting development of civic-mindedness supports empathy in DPT students.14,15 Educational content designed to improve empathy could potentially be added to DPT curricula to benefit students. Empathy is an important subcomponent of emotional intelligence (EI), and a significant correlation has been shown between El and examination performance in medical students (Austin).2,16,17 Other studies found mixed results regarding the correlation between empathy levels and academic performance, indicating a need for further research. 4,8

It is theorized that empathy plays a large role in the patient's perceived quality of care.2,8 Physical therapists spend significant amounts of time with their patients. As a result, the physical therapist's ability to express empathy and effectively communicate with patients is critical. During graduate school, many physical therapy students have patient interaction exposure in the form of practical examinations. These "patients" may be classmates, faculty members, or volunteers from the community. A practical examination involves demonstration of clinical skills and can include a student completing a full evaluation with treatment, patient education, and design of a home exercise program. This allows students to understand patient treatment expectations before beginning clinical rotations. To date, no study has explored the correlation of empathy and practical examination scores in DPT students. We hypothesize a correlation between empathy and practical examination scores in DPT students exists. A positive correlation could inform further research on this topic, potentially leading to DPT programs incorporating empathy training into their curricula. The aim of this study was to examine the possibility of a correlation between empathy and practical examination scores of DPT students.

\section{METHODS \\ Participants}

Participants were a convenience sample of 49 first and second year Doctor of Physical Therapy (DPT) students (26 females, 23 males) ages 23-35, from Franklin Pierce University (FPU) in Goodyear, Arizona. Approval from the Franklin Pierce University Institutional Review Board was granted prior to data collection.

\section{Data Collection}

Study participants provided consent and were then administered the Interpersonal Reactivity Index (IRI). Students were emailed a link to an encrypted server providing access to the study consent form outlining the purpose of the study and the IRI. The link was sent after all practical examinations included in the study were completed. If students voluntarily decided to participate and signed the consent form, they then proceeded to complete the IRI. This reliable and valid survey comprises 28 statement items divided equally into four different subscales including the following: Perspective Taking, Fantasy, Empathic Concern, and Personal Distress. Responses to survey items were recorded using a Likert Scale ranging from "Does not describe me well" to "Describes me very well" with corresponding scores of $0-4.3,18,19$ Reverse-scoring is used for 9 of the 28 items with corresponding scores of 4$0.3,18$ The IRI offers a multidimensional assessment of empathy into four subscales. This provides an in-depth evaluation of empathy, and for this reason, it was utilized to measure empathy in this study. ${ }^{3,19}$ All practical examinations used in the study were graded by professors, with no patient input used. 


\section{Data Analysis}

Practical examination scores were compared with empathy scores using a Spearman Rho analysis using SPSS version 25 .

\section{RESULTS}

All testing and scoring were performed at Franklin Pierce University in Goodyear, Arizona with informed consent obtained from each subject prior to participation. Participants individually completed the IRI to assess personal empathy. These scores were deidentified by the principal investigator and results were calculated using the 0-4 scale for positively scored items and 4-0 scale for negatively scored items denoted in the IRI. ${ }^{3}$ See Table 1 for all scored items. Scores of seven different practical examinations from Foundations of Physical Therapy I \& II and Musculoskeletal System I \& II courses at Franklin Pierce University were collected by the principal investigator for each participant. Four of the seven practical examinations used volunteer patients and three of the practical examinations used classmate patients. These specific practical examination scores were utilized as they included scoring for patient interactions. Results from the IRI survey and the seven practical examinations were analyzed for potential relationships between empathy levels and practical examination scores using Spearman Rho correlation.

Table 1. Positive and Negative IRI Scoring; PT-Perspective Taking, FS-Fantasy, EC-Empathic Concern, PD-Personal Distress

\begin{tabular}{|c|c|}
\hline Positively Scored Items & Negatively Scored Items \\
\hline $\begin{array}{l}\text { I daydream and fantasize, with some regularity, about things that } \\
\text { might happen to me. (FS) }\end{array}$ & $\begin{array}{l}\text { I sometimes find it difficult to see things from the "other guy's" point of } \\
\text { view. (PT) }\end{array}$ \\
\hline $\begin{array}{l}\text { I often have tender, concerned feelings for people less fortunate } \\
\text { than me. (EC) }\end{array}$ & $\begin{array}{l}\text { Sometimes I don't feel very sorry for other people when they are } \\
\text { having problems. (EC) }\end{array}$ \\
\hline $\begin{array}{l}\text { I really get involved with the feelings of the characters in a novel. } \\
\text { (FS) }\end{array}$ & $\begin{array}{l}\text { I am usually objective when I watch a movie or play, and I don't often } \\
\text { get completely caught up in it. (FS) }\end{array}$ \\
\hline In emergency situations, I feel apprehensive and ill-at-ease. (PD) & $\begin{array}{l}\text { I am usually objective when I watch a movie or play, and I don't often } \\
\text { get completely caught up in it. (FS) }\end{array}$ \\
\hline $\begin{array}{l}\text { I try to look at everybody's side of a disagreement before I make a } \\
\text { decision. (PT) }\end{array}$ & $\begin{array}{l}\text { Becoming extremely involved in a good book or movie is somewhat } \\
\text { rare for me. (FS) }\end{array}$ \\
\hline $\begin{array}{l}\text { When I see someone being taken advantage of, I feel kind of } \\
\text { protective towards them. (EC) }\end{array}$ & When I see someone get hurt, I tend to remain calm. (PD) \\
\hline $\begin{array}{l}\text { I sometimes feel helpless when I am in the middle of a very } \\
\text { emotional situation. (PD) }\end{array}$ & $\begin{array}{l}\text { Other people's misfortunes do not usually disturb me a great deal. } \\
\text { (EC) }\end{array}$ \\
\hline $\begin{array}{l}\text { I sometimes try to understand my friends better by imagining how } \\
\text { things look from their perspective. (PT) }\end{array}$ & $\begin{array}{l}\text { If I'm sure I'm right about something, I don't waste much time } \\
\text { listening to other people's arguments. (PT) }\end{array}$ \\
\hline $\begin{array}{l}\text { After seeing a play or movie, I have felt as though I were one of the } \\
\text { characters. (FS) }\end{array}$ & $\begin{array}{l}\text { When I see someone being treated unfairly, I sometimes don't feel } \\
\text { very much pity for them. (EC) }\end{array}$ \\
\hline Being in a tense emotional situation scares me. (PD) & I am usually pretty effective dealing with emergencies. (PD) \\
\hline \multicolumn{2}{|l|}{ I am often quite touched by things that I see happen. (EC) } \\
\hline \multicolumn{2}{|l|}{$\begin{array}{l}\text { I believe that there are two sides to every question and try to look at } \\
\text { them both. (PT) }\end{array}$} \\
\hline \multicolumn{2}{|l|}{ I would describe myself as a pretty soft-hearted person. (EC) } \\
\hline \multicolumn{2}{|l|}{$\begin{array}{l}\text { When I watch a good movie, I can very easily put myself in the } \\
\text { place of a leading character. (FS) }\end{array}$} \\
\hline I tend to lose control during emergencies. (PD) & \\
\hline
\end{tabular}




\begin{tabular}{|c|c|}
\hline $\begin{array}{l}\text { When I'm upset at someone, I usually try to "put myself in his shoes" } \\
\text { for a while. (PT) }\end{array}$ & \\
\hline $\begin{array}{l}\text { When I am reading an interesting story or novel, I imagine how I } \\
\text { would feel if the events in the story were happening to me. (FS) }\end{array}$ & \\
\hline $\begin{array}{l}\text { When I see someone who badly needs help in an emergency, I go } \\
\text { to pieces. (PD) }\end{array}$ & \\
\hline $\begin{array}{l}\text { Before criticizing somebody, I try to imagine how I would feel if I } \\
\text { were in their place. (PT) }\end{array}$ & \\
\hline
\end{tabular}

\section{Sample Characteristics}

Participants included 26 females and 23 males with a mean age of $27.2 \pm 3.34$. Furthermore, the sample was composed of 23 first-year (PY1) students and 26 second-year (PY2) students. A Mann-Whitney $U$ test showed that effects of sex differences ( $p=.27$ ) and graduate year $(p=.42)$ on empathy scores were insignificant for the first-year students. Likewise, the Mann-Whitney $U$ test showed that effects of sex differences $(p=.15)$ and graduate year $(p=.61)$ on practical examination scores were insignificant for second-year students as well.

\section{Practical Examination Scores}

Mean practical examination score for all study participants was calculated to be $92.49 \% \pm 0.02$. Practical examination scores were taken from Foundations of Physical Therapy I \& II and Musculoskeletal System I \& II courses offered in the first three terms of the academic program. Before each practical examination, students were provided a rubric that clearly stated expectations regarding personal and professional interactions with patients. Points were allotted for various personal interactions including addressing the patient appropriately and politely, building rapport, paying attention, actively listening, demonstrating appropriate body language, and utilizing empathy. Rubrics contained elements related to each of the four subscales included in the IRI. The total score from each practical examination was utilized for analysis.

\section{Empathy Data}

The mean empathy score for all 49 subjects determined from the IRI was $72.80 \pm 18.66$.

Table 2. Scores and Correlation Results

\begin{tabular}{|l|l|l|l|}
\hline Item & First Year Students & Second Year Students & p value \\
\hline Practical Examination & $92.7 \% \pm .05$ & $92.3 \% \pm .13$ & 0.61 \\
\hline Empathy Score & $72.15 \pm 4.66$ & $73.38 \pm 5.54$ & 0.42 \\
\hline
\end{tabular}

\section{Correlations}

Mean IRI empathy scores and mean practical examination scores were calculated and can be found in Table 2. Significance was found with Spearman Rho correlation between empathy levels and practical examination scores for all participants with $\mathrm{r}_{\mathrm{s}}=$ $0.864(p<0.000)$. According to Cohen, an $r_{s}$ value of 0.8 with 49 subjects has greater than $98 \%$ power, strongly supporting the sample size and results of this study (Cohen). ${ }^{20}$ 
Table 3. Correlation Analysis.

\begin{tabular}{|l|l|l|l|}
\hline $\begin{array}{l}\text { Practical Examination } \\
\text { Score }\end{array}$ & Empathy Score & Spearman Rho (Rs) & $p$-value \\
\hline $92.5 \% \pm .02$ & $72.80 \pm 18.66$ & $0.864^{*}$ & 0.000 \\
\hline
\end{tabular}

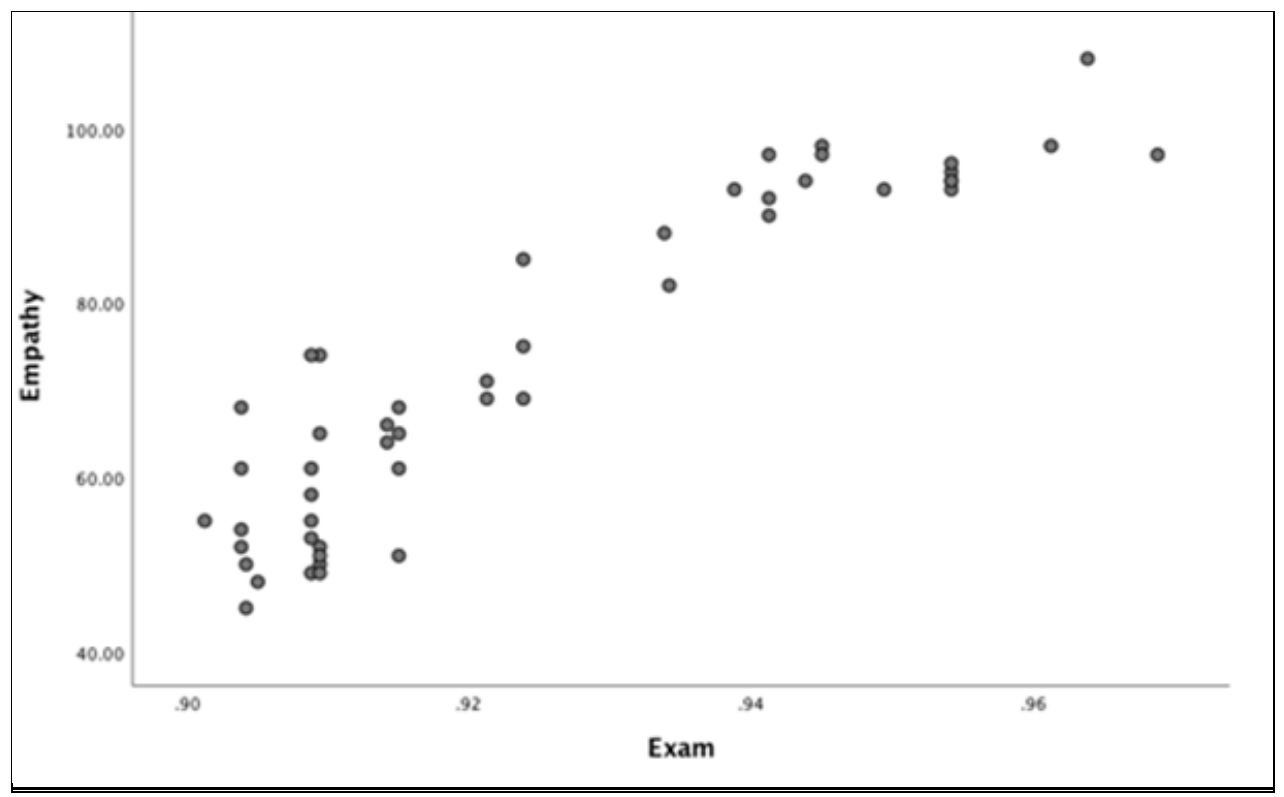

Figure 1. Scatterplot of Results

\section{DISCUSSION}

The purpose of this study was to explore relationships between empathy levels and practical examination scores in DPT students and to provide initial data for this area of research. The outcomes of this study show a strong positive correlation between empathy and practical examination scores. Implications of these findings are consideration of DPT curricular content to develop these abilities in DPT students. Evidence also exists supporting the possibility of increasing empathy with training interventions ${ }^{13}$ (Mueller), and supporting empathy with service-learning experiences. ${ }^{15}$ Research has been completed related to development of a tool to measure non-cognitive attributes of DPT applicants. ${ }^{21}$ Results of the present study support attention to additional admissions criteria.

Findings of this study indicate a need for additional research examining the role of empathy in DPT students and clinicians. Future research can investigate specific skills affecting clinical empathy scores such as determining if students notice non-verbal communication from patients or if they are aware of non-verbal patient cues but do not know how to effectively respond. Students may be aware of the feelings of their patient but have not learned how to use empathetic and reflective statements to communicate effectively. During the admission process, clinical empathy of prospective applicants could be assessed. This information could possibly be used to give insight into students' possible success within their program. Another potential application of these findings could include assessment of clinical empathy levels of DPT students giving faculty opportunities to provide training to improve these skills as needed.

\section{Limitations}

Several limitations should be considered when assessing the results of this study. First, the IRI is a subjective report of empathy and responses could be influenced by how a participant wishes to be perceived. ${ }^{3}$ Second, practical examinations are structured differently among all DPT programs, and therefore, generalization of results is difficult. Also, it has been shown that variations in empathy levels exist among DPT student cohorts, making generalization of results difficult. ${ }^{7}$ Some programs may incorporate empathic components into their rubrics whereas other programs may not address these areas. Despite differences between DPT curricula, the evidence presented in this study highlights the importance of empathy for physical therapists and merits continued 
research activity. Third, data from practical examinations in this study came solely from faculty grading. Future research could incorporate measurement of patient perceptions of empathy during practical examinations and clinical rotations. Finally, scores from specific portions of each practical examination dealing directly with patient interactions could have been separated from other areas scored. This would remove influence on overall scores affected by demonstration of skills unrelated to the study focus.

\section{CONCLUSION}

Physical therapy is a unique profession involving high levels of interaction between clinicians and patients. Paramount to meaningful physical therapy treatment is open and honest communication in which empathy plays a critical role. This study examined the correlation between empathy and practical examination scores. We hypothesized that higher levels of empathy would correlate with higher practical examination scores. The present study provides interesting preliminary findings that may support inclusion of empathy training in DPT curricula.

\section{References}

1. Coulehan JL, Platt FW, Egener B, et al. "Let me see if I have this right." Words that help build empathy. Ann Intern Med. Aug 7 2001;135(3):221-227.

2. Austin EJ, Evans P, Goldwater R, Potter V. A preliminary study of emotional intelligence, empathy, and exam performance in first year medical students. Personality and Individual Differences. 2005;39(8):1395-1405. doi:10.1016/j.paid.2005.04.014.

3. Lucas-Molina B, Pérez-Albéniz A, Ortuño-Sierra J, Fonseca-Pedrero E. Dimensional structure and measurement invariance of the Interpersonal Reactivity Index (IRI) across gender. Psicothema. 2017; 29(4), 590-595.

4. Mercer SW, Reynolds WJ. Empathy and quality of care. Br J Gen Pract. 2002;52 Suppl(Suppl):S9-S12.

5. Wilson SE, Prescott J, Becket G. Empathy levels in first-and third-year students in health and non-health disciplines. Am J Pharm Educ. 2012; 76(2).

6. Lee CR. Park M. (2018). Analysis of Empathy in Physical Therapy Students. Journal of International Academy of Physical Therapy Research. 2018; 9(4), 1586-1590.

7. Gabard D L, Lowe DL, Deusinger SS, Stelzner DM, Crandall SJ. Analysis of Empathy in Doctor of Physical Therapy Students A Multi-Site Study. Journal of allied health. 2013;42(1), 10-16.

8. Hojat M, Gonnella JS, Mangione S, et al. Empathy in medical students as related to academic performance, clinical competence and gender. Medical Education. 2002;36(6):522-527. doi:10.1046/j.1365-2923.2002.01234. BattRawden, S. A.,

9. Davis CM. What is empathy, and can empathy be taught? Phys Ther. 1990;70(11):707-711

10. Cunico L, Sartori R, Marognolli O, Meneghini AM. Developing empathy in nursing students: a cohort longitudinal study. Journal of Clinical Nursing. 2012; 21(13-14), 2016-2025.

11. Chisolm MS, Anton B, Flickinger TE. Teaching empathy to medical students: an updated, systematic review. Academic Medicine. 2013; 88(8), 1171-1177.

12. Batt-Rawden SA, Chisolm MS, Anton B, Flickinger TE. Teaching empathy to medical students: an updated, systematic review. Academic Medicine. 2013; 88(8), 1171-1177.

13. Mueller $\mathrm{K}$, Prins $\mathrm{R}$, de Heer $\mathrm{H}$. An online intervention increases empathy, resilience, and work engagement among physical therapy students. Journal of Allied Health. 2018; 47(3), 196-203.

14. Village D. Qualities of effective service learning in physical therapist education. Journal of Physical Therapy Education. 2006; 20(3), 8-17.

15. Palombaro KM, Black JD, Dole RL, Jones SA, Stewart AR Civic-mindedness sustains empathy in a cohort of physical therapy students: a pilot cohort study. Journal of Patient Experience. 2020; 7(2), 185-192.

16. Goleman D. Emotional Intelligence. New York, NY: Bantam Books; 1995

17. Greif EB, Hogan R. The theory and measurement of empathy. J Counseling Psychol. 1973;20(3):280-284.

18. Davis MH. A multidimensional approach to individual differences in empathy. JSAS Catalog of Selected Documents in Psychology. 1980; 10, 85.

19. Pulos S, Elison J, Lennon R. The hierarchical structure of the Interpersonal Reactivity Index. Social Behavior and Personality: An International Journal. 2004;32(4):355-359. doi:10.2224/sbp.2004.32.4.355

20. Cohen J. Statistical Power Analysis for the Behavioral Sciences ed 2 Hillsdale, NJ: Lawrence Erlbaum Associates 1988.

21. Roll M, Canham L, Salamh P, Covington K, Simon C, Cook C. A novel tool for evaluating non-cognitive traits of doctor of physical therapy learners in the United States. Journal of Educational Evaluation for Health Professions. 2018; 15. 